\title{
Biological Characterization of SB3, a Trastuzumab Biosimilar, and the Influence of Changes in Reference Product Characteristics on the Similarity Assessment
}

\author{
Jae Hee Lee ${ }^{1}$ [ $\cdot$ Kyungyeol Paek ${ }^{1}$ Jae Hyon Moon ${ }^{1}$. Sunyoung Ham ${ }^{1}$. Jinsu Song ${ }^{1}$ - Seokkyun Kim ${ }^{1}$
}

Published online: 12 June 2019

(c) The Author(s) 2019

\begin{abstract} cal profile of the reference product on similarity assessment. lyzed during the developmental period of SB3.

\section{Introduction}

A biosimilar is a biological medicinal product with structural and functional properties that are highly similar to an authorized and already approved original biological drug, and whose pharmacokinetics and clinical activity are shown to be similar in a comparative clinical trial [1]. The European Medicines Agency (EMA) and United States (US) Food and Drug Administration (FDA) have developed
\end{abstract}

Background SB3 has been developed as a trastuzumab biosimilar, a therapeutic monoclonal antibody targeted to human epidermal growth factor receptor 2 (HER2), and approved by the European Commission and United States (US) Food and Drug Administration (FDA). During the developmental period of a biosimilar, setting an appropriate quality target is critical for assessing the similarity of the biosimilar product to the reference product. A stepwise approach should be taken to assessing similarity, beginning with extensive characterization of the reference product to establish the quality target.

Objective In this study, we evaluated the similarity of SB3 to the reference product and the impact of changes in the biologi-

Methods Analytical similarity was assessed with defined test procedures in terms of critical quality attributes (CQAs) that could affect efficacy, potency, and safety, as well as for the non-CQAs that are related to process consistency. The quality target was established using up to 154 lots of European Union (EU)- and US-sourced Herceptin ${ }^{\circledR}$ (reference product), ana-

Results Trends of the EU- and US-sourced reference product showed that the biological profile exhibited two marked changes for Fc-related attributes, and then recovered to pre-change quality level. Since the similarity range set by pre-change lots was considered most relevant, the changed lots were excluded from establishing the similarity range, which resulted in tightened acceptance criteria. As shown in the results of similarity assessment using the stringent quality target ranges, SB3 exhibits highly similar functional activities compared to the reference product in terms of both CQAs and non-CQAs.

Conclusion SB3 has been developed as a trastuzumab biosimilar approved in the EU and USA, and its manufacturing process is deemed to be robust and well-controlled within stringent quality target ranges.

Jae Hee Lee

jaehee81.lee@samsung.com

1 Quality Evaluation Team, Samsung Bioepis Co., Ltd, 107, Cheomdan-daero, Yeonsu-gu, Incheon 21987, Republic of Korea

\section{Key Points}

Up to 154 lots of Herceptin ${ }^{\circledR}$ (reference product) were analyzed for the characterization of the trastuzumab biosimilar SB3. After two sequential changes in the biological profile in both EU- and US-sourced reference product, the attributes recovered to pre-change levels.

Considering the influence of biological profile changes on the range, the quality target was tightened for similarity assessment by excluding the lots where the biological profile had changed.

SB3 demonstrated high similarity in critical biological quality attributes, including Fab-related biological activities, effector functions such as direct mechanism of action-related antibody-dependent cell-mediated cytotoxicity (ADCC) and Fcy receptor IIIa binding, and neonatal $\mathrm{Fc}$ receptor $(\mathrm{FcRn})$ binding that may affect its half-life. 
biosimilar guidelines, with a requirement to demonstrate the totality of evidence including analytical, non-clinical, and clinical similarity [2-7]. Analytical similarity in structural and functional properties is critical to expect the absence of any meaningful difference in clinical outcomes. Based on this fundamental assumption, a similarity assessment should be performed by a stepwise approach, starting with extensive physicochemical and biological characterization of both the biosimilar and the reference product [2,3]. Studies for analytical similarity should be based on analytical data with defined test procedures and acceptance criteria for the reference product's critical quality attributes (CQAs) that could affect efficacy, potency, and safety, as well as for non-CQAs that are related to process consistency [4].

Human epidermal growth factor receptor 2 (HER2) is a membrane-bound receptor protein that promotes cell growth and division when activated by ligand binding. In approximately $20-25 \%$ of breast cancers, HER 2 is overexpressed, associated with faster growth of the cancer and a higher recurrence rate [8]. Trastuzumab is a therapeutic monoclonal antibody (mAb) of the IgG1 subclass with a kappa light chain, specifically targeted to HER2. Since trastuzumab was developed by humanizing the parental murine antibody "4D5," it contains a human framework region and the complementarity-determining regions of a murine antibody that binds to the domain IV region of HER2 [9]. HER2 is activated by dimerization, which leads to the activation of the Ras/Raf/mitogen-activated protein kinase (MAPK), phosphoinositide 3-kinase (PI3K)/Akt, and phospholipase $\mathrm{C} \gamma(\mathrm{PLC} \gamma) /$ protein kinase $\mathrm{C}$ pathways required for the cell proliferation $[10,11]$. The mechanism of action (MoA) of trastuzumab is known to be its inhibition of proliferation of HER2-overexpressing cells by blocking MAPK and PI3K/ Akt pathways $[12,13]$. Another major mechanism of trastuzumab is to attract immune cells to HER2-overexpressing tumor sites, called antibody-dependent cell-mediated cytotoxicity (ADCC) $[14,15]$. Upon antigen binding to mAbs, effector functions are mediated by their $\mathrm{Fc}$ part that binds to $\mathrm{Fc} \gamma$ receptor $(\mathrm{Fc} \gamma \mathrm{R})$ IIIa ( $\mathrm{Fc} \gamma \mathrm{RIII}$, also known as CD16a). The $N$-glycosylation pattern of mAbs influences the binding affinity of its Fc part to FcyRIIIa. Trastuzumab also induces HER2 internalization and degradation through binding to HER2 [16].

Trastuzumab was approved by the US FDA in 1998 and by the European Commission (EC) in 2000 for the treatment of certain patients with breast cancers overexpressing HER2 under the trade name Herceptin ${ }^{\circledR}$ (hereafter called "reference product") [17]. In addition, as a combination therapy, trastuzumab plus chemotherapy regimen has become the standard of care for the treatment of HER2-positive breast cancers, providing significant clinical benefit in adjuvant settings against early as well as advanced or metastatic breast cancers [18-20].
SB3 was developed as a trastuzumab biosimilar by Samsung Bioepis Co., Ltd. (Incheon, Republic of Korea), and approved by the EC in Nov 2017 and by the US FDA in Jan 2019, for the treatment of HER2-positive breast cancer and HER2-overexpressing gastric cancer. In the Republic of Korea and Australia, SB3 was approved by the Ministry of Food and Drug Safety and the Therapeutic Goods Administration in November 2017 and December 2018, respectively. In accordance with the International Conference on Harmonisation (ICH) Q8 (R2) guideline, a risk assessment was conducted to establish the CQAs for SB3 on the basis of the MoA for trastuzumab and the analytical capability of state-of-the-art methods. Risk priority number (RPN) is scored for the impact and uncertainty of attributes on efficacy and safety, and applied to evaluate the CQAs. The CQAs of SB3 were established based on impacts not only on HER 2 binding and the subsequent anti-proliferation effect, but also on its effector functions associated with the Fc domain in general.

To demonstrate the similarity of SB3 to the reference product, an extensive analytical characterization was executed based on the quality target profile established during the developmental period. During the characterization study of SB3, up to 154 lots of reference product were analyzed, and two sequential changes in Fc-related attributes such as the sum value of \%afucose $+\%$ high mannose, FcyRIIIa binding, ADCC, and \%galactosylation $(\mathrm{G} 1 \mathrm{~F}+\mathrm{G} 2 \mathrm{~F})$ were observed in both EU- and US-sourced reference product expiring between August 2018 and December 2019 [21]. Herein, the analytical similarity of SB3 was assessed with the stringent quality target ranges set by excluding the lots of reference product demonstrating biological profile changes. The results demonstrate that SB3 is highly similar to the reference product in terms of biological quality attributes.

\section{Materials and Methods}

\subsection{Materials}

EU- and US-sourced reference product (up to 154 lots) were purchased from local distributors and then stored according to the manufacturer's instructions. The reference standard for the bioassays was prepared from EU-sourced reference product and used for characterization of the reference products and SB3. The CellTiter-Blue ${ }^{\circledR}$ and CytoTox-Glo ${ }^{\circledR}$ kits were obtained from Promega (Madison, WI, USA). The PNGase-F kit was obtained from New England Biolabs (NEB, Ipswich, MA, USA). The 2-aminobenzamide (2-AB) labelling kit for $N$-glycan analysis was obtained from Ludger (Oxfordshire, UK). Glutathione (GSH)-coated donor beads, human IgG-conjugated acceptor beads, and streptavidin-coated donor beads were obtained from PerkinElmer 
(Waltham, MA, USA). The glutathione- $S$-transferase (GST)tagged Fc $\gamma$ RIIIa and HER2-Fc were obtained from Biogen (Cambridge, MA, USA). Biotin-labelled neonatal Fc receptor (FcRn) was obtained from Biogen (Cambridge, MA, USA). C1q protein was obtained from Quidel (San Diego, CA, USA). Anti-C1q horseradish peroxidase (HRP) conjugated antibody (catalog number AB46191) was obtained from Abcam (Cambridge, MA, USA). Statistical analysis and graphical comparison were performed with Minitab statistic software package (Leadtools Technologies Inc., version 18.1.0, Charlotte, NC, USA).

\subsection{Cell Lines and Cell Culture}

SKBR3 cells were obtained from American Type Culture Collection (ATCC, Manassas, VA, USA) and incubated at $37{ }^{\circ} \mathrm{C}, 5 \% \mathrm{CO}_{2}$ in McCoy's 5A (Gibco, Grand Island, NY, USA) containing $10 \%$ fetal bovine serum (FBS) (Hyclone, Logan, UT, USA). BT474 cells were obtained from ATCC and incubated at $37{ }^{\circ} \mathrm{C}, 5 \% \mathrm{CO}_{2}$ in Dulbecco's Modified Eagle Medium: Nutrient Mixture F-12 (DMEM/F12, Gibco) containing 10\% FBS. NK92-CD16 cells were obtained from Biogen (Cambridge, MA, USA) and incubated at $37^{\circ} \mathrm{C}, 5 \%$ $\mathrm{CO}_{2}$ in Myelocult $\mathrm{H} 5100$ (Stemcell Technology, Vancouver, Canada) containing human interleukin-2 (Cell Signaling Technology, Beverly, MA, USA) and puromycin (Gibco).

\subsection{Anti-proliferation Assay}

The anti-proliferation potency was measured by CellTiterBlue ${ }^{\circledR}$ cell viability assay kit (Promega) according to manufacturer's instruction. BT474 cells were incubated with ten serially diluted concentrations $(0.008-1.0 \mu \mathrm{g} / \mathrm{mL})$ of trastuzumab for 4 days at $37{ }^{\circ} \mathrm{C}, 5 \% \mathrm{CO}_{2}$ in DMEM/F12 containing $10 \%$ FBS. The relative number of viable cells was quantified by measuring the fluorescence (excitation at $560 \mathrm{~nm}$ and emission at $590 \mathrm{~nm}$ ) using a SpectraMax ${ }^{\circledR}$ M3 (Molecular Devices, San Jose, CA, USA). Data were analyzed using Parallel Line Analysis 2.0 (PLA) software (Stegmann Systems GmbH, Rodgau, Germany) to calculate relative anti-proliferation potency.

\subsection{ADCC Assay}

The ADCC assay was performed to assess Fc-related biological activity of trastuzumab against a HER2-overexpressing human breast cancer cell line (SKBR3). NK92-CD16 cells, a human natural killer cell line expressing CD16, were used as effector cells. Experimentally, trastuzumab was incubated with SKBR3 and NK92-CD16 cells in flat-bottom 96-well plates for $4 \mathrm{~h}$ at $37{ }^{\circ} \mathrm{C}, 5 \% \mathrm{CO}_{2}$ in McCoy's $5 \mathrm{~A}$ medium. After incubation, the SKBR3/NK92-CD16/sample mixture was incubated with a luminogenic peptide substrate (alanyl-alanyl-phenylalanyl-aminoluciferin; AAF-Glo Substrate) as a part of the CytoTox-Glo ${ }^{\circledR}$ kit. The luminescence signals (dead cell signals) were quantified by an Envision ${ }^{\mathrm{TM}}$ Multilabel Plate Reader (PerkinElmer). Data were analyzed by using PLA software to calculate relative ADCC potency.

\subsection{HER2 Binding Assay}

The competitive inhibitory HER2 binding assay was performed using time-resolved fluorescence resonance energy transfer (FRET) technology. When donor chromophore absorbs 340-nm wavelength light, it transfers 615-nm energy to an acceptor chromophore. Then, the acceptor chromophore emits longer wavelength light, and the detector accepts a 665-nm wavelength light. In this system, 12 concentrations $(0.0488-100 \mu \mathrm{g} / \mathrm{mL})$ of trastuzumab were incubated with a fixed volume of Europium chelate-labeled trastuzumab (donor chromophore) and Cy5-labeled HER2 (acceptor chromophore) in assay diluent $[1 \times$ phosphate-buffered saline (PBS), $0.1 \%$ bovine serum albumin (BSA), and $\mathrm{pH}$ 7.4]. The mixture was then incubated at $25^{\circ} \mathrm{C}$ for $1 \mathrm{~h}$ with moderate agitation. After incubation, the fluorescent signal was obtained from the Envision ${ }^{\mathrm{TM}}$ Multilabel Plate Reader (PerkinElmer) at a wavelength of $665 \mathrm{~nm}$. Data were analyzed by using PLA software to calculate the relative binding activity.

\subsection{C1q Binding Assay}

The $\mathrm{C} 1 \mathrm{q}$ binding assay was performed to assess $\mathrm{Fc}$-related biological activity of trastuzumab using sandwich enzymelinked immunosorbent assay (ELISA). In this system, 96-well plates were coated with seven concentrations $(0.391-25 \mu \mathrm{g} / \mathrm{mL})$ of trastuzumab and incubated at $37{ }^{\circ} \mathrm{C}$ for $1 \mathrm{~h}$. Then, the plate was blocked using blocking buffer and incubated at room temperature for $1 \mathrm{~h}$. After blocking, a fixed concentration of C1q (Quidel) solution was added to the plate and the plate was incubated at room temperature. After incubation, fixed concentration of C1q-HRP antibody (Abcam) was added to the plate and the plate was incubated at room temperature. Using 3,3',5,5'-tetramethylbenzidine (TMB) ELISA substrate (Sigma-Aldrich, St. Louis, MO, USA), C1q binding activity was quantified by measuring the absorbance at $450 \mathrm{~nm}$ using a SpectraMax ${ }^{\circledR}$ M3 (Molecular Devices). Data were analyzed by using PLA software to calculate the relative binding activity.

\subsection{FcRn Binding Assay}

The FcRn binding assay was performed to assess Fcrelated biological activity of trastuzumab using Alphascreen $^{\mathrm{TM}}$ technology with active donor and acceptor beads. With excitation, a photosensitizer in a donor bead converts 
ambient oxygen to reactive singlet oxygen. The singlet oxygen species reacts with thioxene compounds in the acceptor bead to generate a chemiluminescent signal that emits at $370 \mathrm{~nm}$. In this system, 12 concentrations $(0.021-200 \mu \mathrm{g} /$ $\mathrm{mL}$ ) of trastuzumab were incubated with a fixed volume of streptavidin-coated donor/human IgG-conjugated acceptor beads and biotin-labelled FcRn in assay diluent $(20 \mathrm{mM}$ 4-morpholineethanesulfonic acid, $150 \mathrm{mM} \mathrm{NaCl}, 0.1 \%$ BSA, pH 5.8). The mixture was incubated at $22{ }^{\circ} \mathrm{C}$ for $2 \mathrm{~h}$ with moderate agitation. After incubation, the fluorescent signal was obtained from the Envision ${ }^{\mathrm{TM}}$ Multilabel Plate Reader (PerkinElmer) with excitation at $680 \mathrm{~nm}$ and reading emission at 520-620 nm. Data were analyzed by using PLA software to calculate the relative binding activity.

\subsection{FcyRla Binding Assay}

The competitive inhibitory Fc $\gamma$ RIa binding assay was performed using time-resolved FRET technology. In this system, 12 concentrations $(0.0257-150 \mu \mathrm{g} / \mathrm{mL})$ of trastuzumab were incubated with a fixed volume of Europium chelatelabeled trastuzumab (donor chromophore) and Cy5-labeled Fc $\gamma$ RIa (acceptor chromophore) in assay diluent $(1 \times \mathrm{PBS}$, $0.1 \% \mathrm{BSA}$, and $\mathrm{pH} 7.4$ ). The mixture was then incubated at $25^{\circ} \mathrm{C}$ for $1 \mathrm{~h}$ with moderate agitation. After incubation, the fluorescent signal was obtained from the Envision ${ }^{\mathrm{TM}}$ Multilabel Plate Reader (PerkinElmer) at a wavelength of $665 \mathrm{~nm}$. Data were analyzed by using PLA software to calculate the relative binding activity.

\subsection{FcyRlla Binding Assay}

The Fc $\gamma$ RIIa binding assay was performed to assess Fcrelated biological activity of trastuzumab using Alphascreen $^{\mathrm{TM}}$ technology. In this system, 12 concentrations $(0.26-166.67 \mu \mathrm{g} / \mathrm{mL})$ of trastuzumab were incubated with a fixed volume of GSH-coated donor/human IgG-conjugated acceptor beads and GST-tagged Fc $\gamma$ RIIa. The mixture was incubated at $22{ }^{\circ} \mathrm{C}$ for $2.0 \mathrm{~h}$ with moderate agitation. After incubation, the fluorescent signal was obtained from the Envision $^{\mathrm{TM}}$ Multilabel Plate Reader (PerkinElmer) with excitation at $680 \mathrm{~nm}$ and reading emission at 520-620 nm. Data were analyzed by using PLA software to calculate the relative binding activity.

\subsection{FcyRIlb Binding Assay}

The Fc $\gamma$ RIIb binding assay was performed to assess Fcrelated biological activity of trastuzumab using Alphascreen $^{\mathrm{TM}}$ technology. In this system, 12 concentrations $(0.8-500 \mu \mathrm{g} / \mathrm{mL})$ of trastuzumab were incubated with a fixed volume of GSH-coated donor/human IgG-conjugated acceptor beads and GST-tagged FcyRIIb. The mixture was incubated at $22{ }^{\circ} \mathrm{C}$ for $2.0 \mathrm{~h}$ with moderate agitation. After incubation, the fluorescent signal was obtained from the Envision $^{\mathrm{TM}}$ Multilabel Plate Reader (PerkinElmer) with excitation at $680 \mathrm{~nm}$ and reading emission at 520-620 nm. Data were analyzed by using PLA software to calculate the relative binding activity.

\subsection{FcyRIIla Binding Assay}

The Fc $\gamma$ RIIIa binding assay was performed to assess Fcrelated biological activity of trastuzumab using Alphascreen $^{\mathrm{TM}}$ technology. In this system, 12 concentrations $(0.0488-100 \mu \mathrm{g} / \mathrm{mL})$ of trastuzumab were incubated with a fixed volume of GSH-coated donor/human IgG-conjugated acceptor beads and GST-tagged Fc $\gamma$ RIIIa. The mixture was incubated at $22^{\circ} \mathrm{C}$ for $3.5 \mathrm{~h}$ with moderate agitation. After incubation, the fluorescent signal was obtained from the Envision $^{\mathrm{TM}}$ Multilabel Plate Reader (PerkinElmer) with excitation at $680 \mathrm{~nm}$ and reading emission at 520-620 nm. Data were analyzed by using PLA software to calculate the relative binding activity.

\subsection{Glycosylation Profile by 2-Aminobenzamide Labeling and HILIC-UPLC Analysis}

$N$-glycan profiles were analyzed using a hydrophilic interaction liquid chromatography-ultra-performance liquid chromatography (HILIC-UPLC) system (Waters, Milford, MA, USA). For quantitative determination, $100 \mu \mathrm{g}$ of sample was denatured using sodium dodecyl sulfate (SDS) and dithiothreitol (DTT) in the PNGase-F enzyme kit (NEB) at $100{ }^{\circ} \mathrm{C}$ for $10 \mathrm{~min}$, and treated with PNGase $\mathrm{F}$ to release $N$-glycans. The released $N$-glycans were separated using protein precipitation with cold ethanol, and the supernatant was dried. The dried $N$-glycans were then labelled with $2-\mathrm{AB}$ for $3 \mathrm{~h}$ using a LudgerTag ${ }^{\mathrm{TM}} 2$-AB glycan labeling kit (Ludger). Samples were injected onto a UPLC BEH glycan column $(2.1 \mathrm{~mm} \times 150 \mathrm{~mm}, 1.7 \mu \mathrm{m})$. The labeled $N$-glycans were separated at a flow rate of $0.5 \mathrm{~mL} / \mathrm{min}$ with mobile phase A (50 mM ammonium formate) and mobile phase B (100\% acetonitrile). The signal was detected using a fluorescence detector (Waters) at the excitation wavelength of $330 \mathrm{~nm}$ and the emission wavelength of $420 \mathrm{~nm}$. Empower ${ }^{\mathrm{TM}} 3$ software (Waters) was used for data processing and calculating the relative peak area.

\section{Results}

\subsection{Risk Assessment and CQA Classification}

To evaluate the criticality of product quality attributes for SB3, a trastuzumab biosimilar functional risk assessment 
was conducted. The potential impact of individual attributes on product potency, efficacy, and safety was scored as well as the uncertainty regarding the impact assessment of the attributes. Based on RPN values scored by impact and uncertainty categories, the quality attributes were categorized by CQA classification and summarized in Table 1 . Nine analytical methods were used for the similarity assessment of SB3. Among them, five quality attributes met the criteria (RPN > 24) for CQA, in which Fab-related biological activities were included as the main MoA of trastuzumab. The effector-function-related attributes, especially ADCC and Fc $\gamma$ RIIIa binding directly related to the MoA of trastuzumab, and FcRn binding that may affect the half-life were also categorized as a CQA.

\subsection{Determination of Quality Target for Biological Activity of SB3}

A previously reported study demonstrated changes in the $\mathrm{N}$-glycan profile, Fc $\gamma$ RIIIa binding activity, and relative ADCC activity of EU- and US-sourced reference product [21]. The attributes for the $N$-glycan profile, FcyRIIIa binding activity, and relative ADCC activity showed two marked changes throughout the monitoring period. In the first instance, \%galactose and \%afucose were decreased. Hereafter, the level of \%high mannose was remarkably elevated, which was defined as the second instance. Since $N$-glycan levels correlate with relative ADCC activity and Fc $\gamma$ RIIIa binding activity is associated with effector binding in the Fc region during ADCC [22], the change in the $N$-glycan profile resulted in a downward shift of ADCC and FcyRIIIa binding activities in the reference product. Since publishing the data by Kim et al. [21], we have kept monitoring the biological profile trend of the reference product. In recent lots (having an expiry date after February 2020), the biological profile of the reference product recovered to a status similar to that of pre-changed lots (Fig. 1). Therefore, it seems that the first and second changes in biological profile in certain periods were abnormal events; considering that ADCC is a major MoA, such changes in the biological profile have the potential to impact clinical efficacy of the reference product. Furthermore, in terms of similarity assessment, this change in the biological profile of the reference product brings about product variability and can affect the consistency of the target similarity range [mean $\pm 3 \mathrm{SD}$ (standard deviation)], as shown especially in Fc-related attributes (Fig. 2).

Accordingly, in this study, the target quality ranges were established by excluding the lots displaying these altered biological profiles and exclusively using pre-change lots in order to appropriately compare SB3 to the reference product.

\subsection{Fab-Related Biological Attributes}

Based on the MoA of trastuzumab, two sets of biological assays were performed to evaluate the Fab-related activities: anti-proliferation assays and HER2 binding assays. Trastuzumab binds to the extracellular domain IV region of HER2, and blocks proteolytic cleavage of the extracellular domain of HER2, leading to downregulation of the MAPK and PI3K/Akt pathways and inhibition of cell proliferation. HER2 binding activity was determined by a FRET-based competitive inhibition binding assay, and the result showed that SB3 is similar to EU- and US-sourced reference product. The mean values of \%relative binding activity for SB3 and EU- and US-sourced reference product were 100\%, 99\%, and $98 \%$, respectively. In addition, HER2 binding activities of all SB3 batches were within the target similarity range set by mean $\pm 3 \mathrm{SD}$, demonstrating promising similarity in

Table 1 Quality attributes and analytical method by CQA classification

\begin{tabular}{|c|c|c|c|c|c|c|}
\hline \multirow[t]{2}{*}{ Category } & \multirow[t]{2}{*}{ Product quality attribute } & \multirow[t]{2}{*}{ Analytical method } & \multicolumn{2}{|c|}{ Risk assessment } & \multirow[t]{2}{*}{ RPN } & \multirow[t]{2}{*}{ CQA classification } \\
\hline & & & Impact $^{\mathrm{a}}$ & Uncertainty $^{\mathrm{b}}$ & & \\
\hline \multirow[t]{2}{*}{ Fab-related biological activity } & Anti-proliferation activity & Cell-based assay & Very high & Moderate & 60 & CQA \\
\hline & HER2 binding activity & FRET & Very high & Moderate & 60 & CQA \\
\hline \multirow[t]{7}{*}{ Fc-related biological activity } & $\mathrm{ADCC}$ & Cell-based assay & High & Moderate & 48 & CQA \\
\hline & Fc $\gamma$ RIIIa binding activity & AlphaScreen ${ }^{\circledR}$ & High & Moderate & 48 & CQA \\
\hline & Fc $\gamma$ RIa binding activity & AlphaScreen ${ }^{\circledR}$ & Moderate & Low & 24 & Non-CQA \\
\hline & Fc $\gamma$ RIIa binding activity & AlphaScreen ${ }^{\circledR}$ & Moderate & Low & 24 & Non-CQA \\
\hline & Fc $\gamma$ RIIb binding activity & AlphaScreen ${ }^{\circledR}$ & Moderate & Low & 24 & Non-CQA \\
\hline & FcRn binding & AlphaScreen ${ }^{\circledR}$ & High & Moderate & 48 & CQA \\
\hline & $\mathrm{C} 1 \mathrm{q}$ binding & ELISA & Moderate & Low & 24 & Non-CQA \\
\hline
\end{tabular}

$A D C C$ antibody-dependent cell-mediated cytotoxicity, $C Q A$ critical quality attribute, ELISA enzyme-linked immunosorbent assay, $F c R n$ neonatal Fc receptor, FRET fluorescence resonance energy transfer, $H E R 2$ human epidermal growth factor receptor $2, R P N$ risk priority number

${ }^{a}$ Impact was scored by 5 categorizations as very low, low, moderate, high, and very high

${ }^{\mathrm{b}}$ Uncertainty was scored by 4 categorizations as low, moderate, high, and very high 
HER2 binding activity (Fig. 3a). For the anti-proliferation assay, the CellTiter-Blue ${ }^{\circledR}$ kit was used to indicate cell viability in the HER2-overexpressing human breast cancer cell line BT474. The mean values of \%relative anti-proliferation potency for SB3 and EU- and US-sourced reference product were $96 \%, 100 \%$, and $100 \%$ respectively. All SB3 batches also showed relative potencies within the similarity range, demonstrating promising similarity in anti-proliferation
(A)

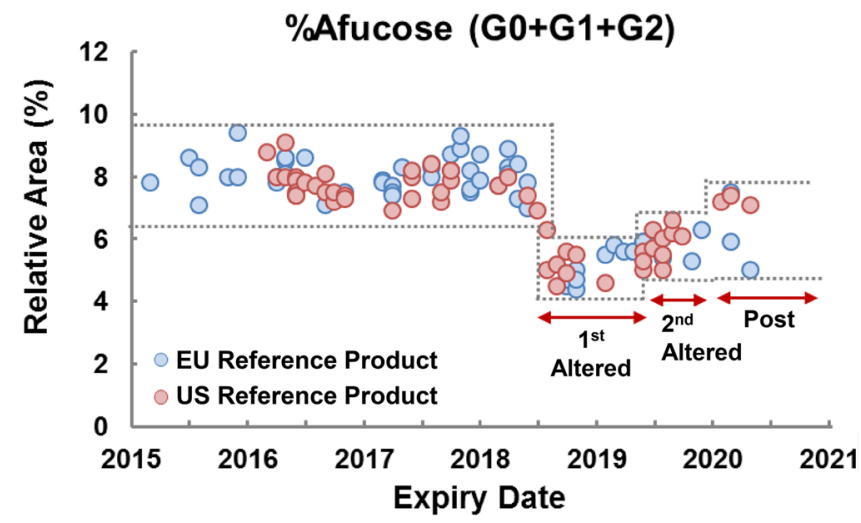

(C)

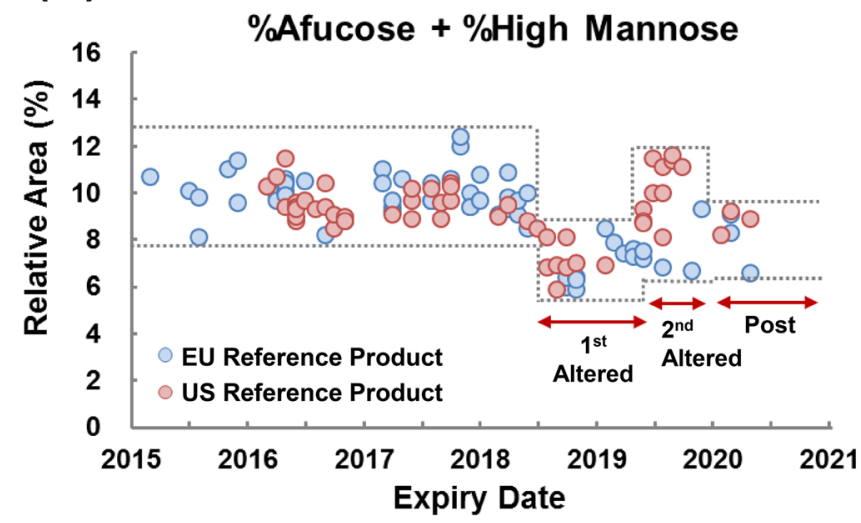

(E)

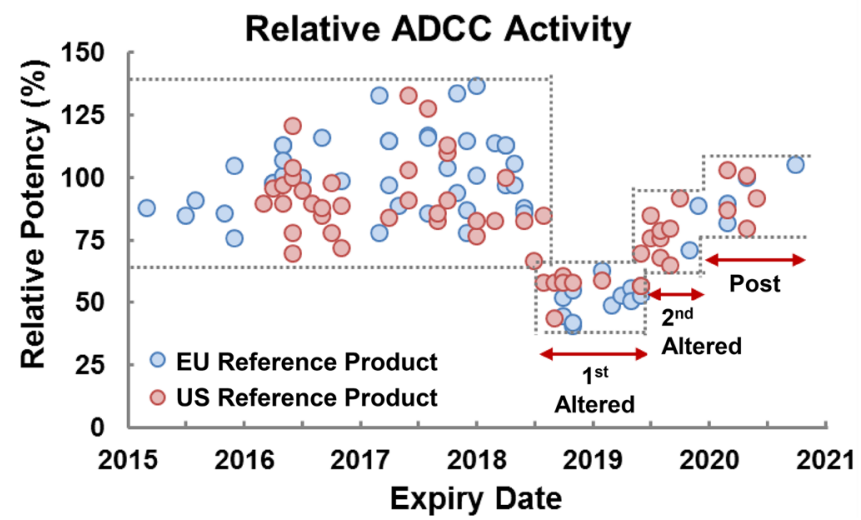

Fig. 1 Trends of Fc-related biological attributes of the reference product. Dotted line shows the min-max range of expiry date before August 2018, 1st alteration, 2nd alteration, and post-alteration. a \%Afucose, b \%high mannose, c \%afucose +\%high mannose, d
(B)

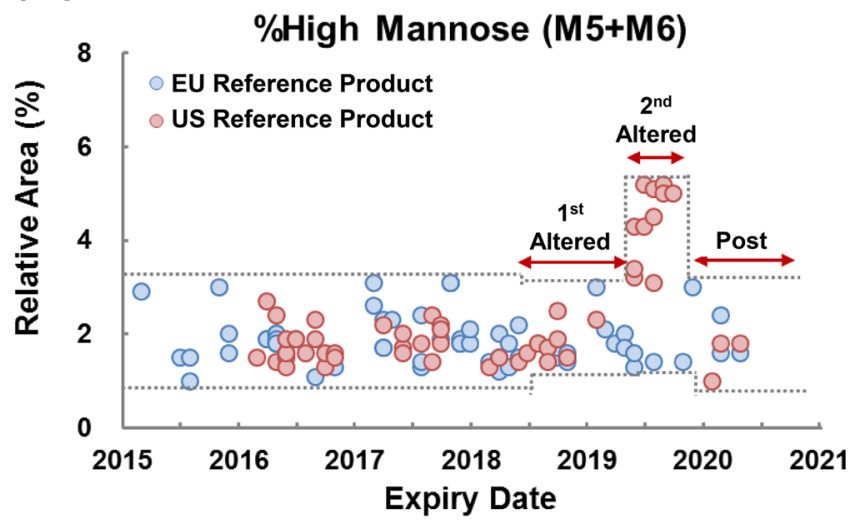

(D)

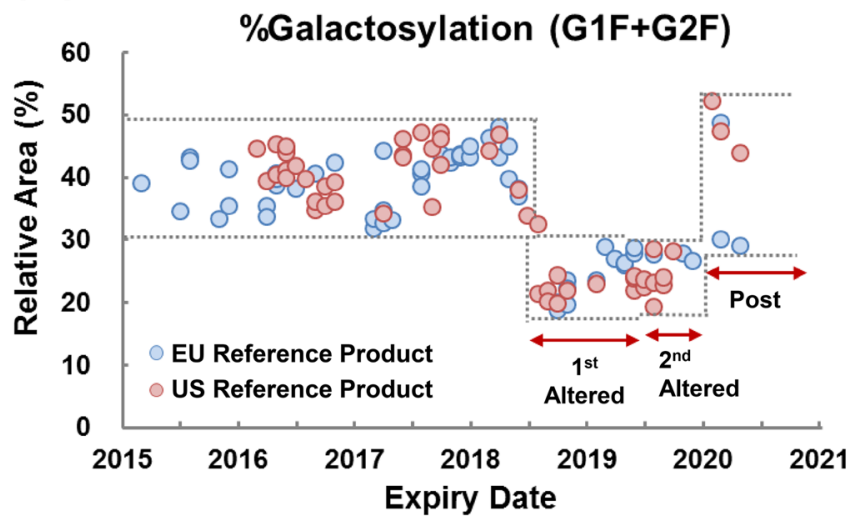

(F)

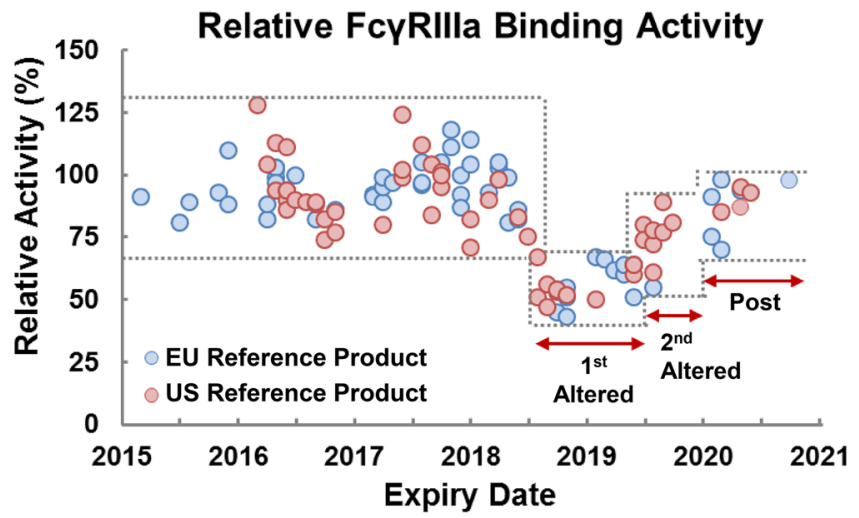

\%galactosylation $(\% \mathrm{G} 1 \mathrm{~F}+\% \mathrm{G} 2 \mathrm{~F})$, e ADCC activity, and f Fc $\gamma$ RIIIa binding activity. $A D C C$ antibody-dependent cell-mediated cytotoxicity, $F c \gamma R$ Fc $\gamma$ receptor, G1F FA2[3]G1 or FA2[6]G1, G2F FA2G2, M5 Mannose5, Man5, M6 Mannose6, Man6 
Fig. 2 Change of target ranges depending on the biological profile change periods of reference product. Boxplots show the mean \pm 3 SD ranges of EU- and US-sourced reference product for pre-alteration, altered, and post periods. a ADCC activity, b FcyRIIIa binding activity, c anti-proliferation activity, and $\mathbf{d}$ HER 2 binding activity. $A D C C$ antibody-dependent cellmediated cytotoxicity, HER2 human epidermal growth factor receptor 2, $F c \gamma R$ Fc $\gamma$ receptor, $S D$ standard deviation
(A)
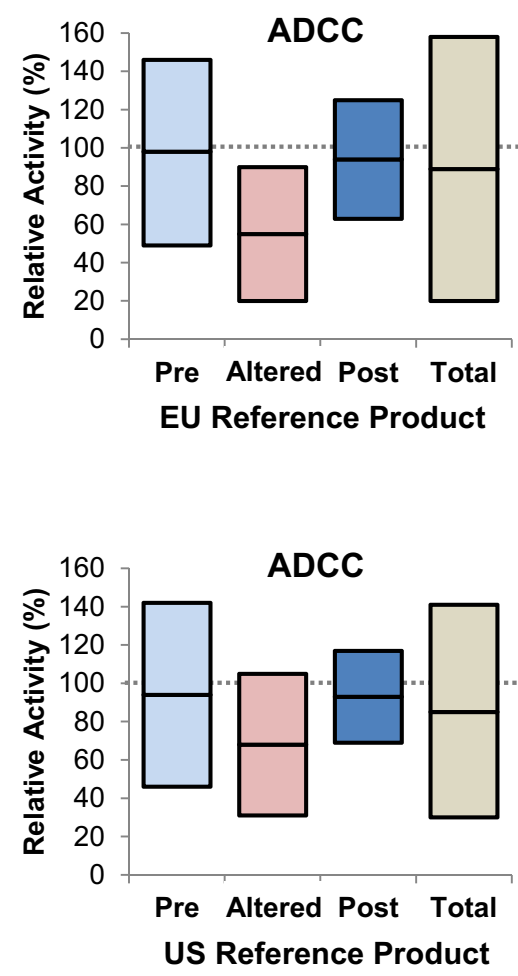

(C)
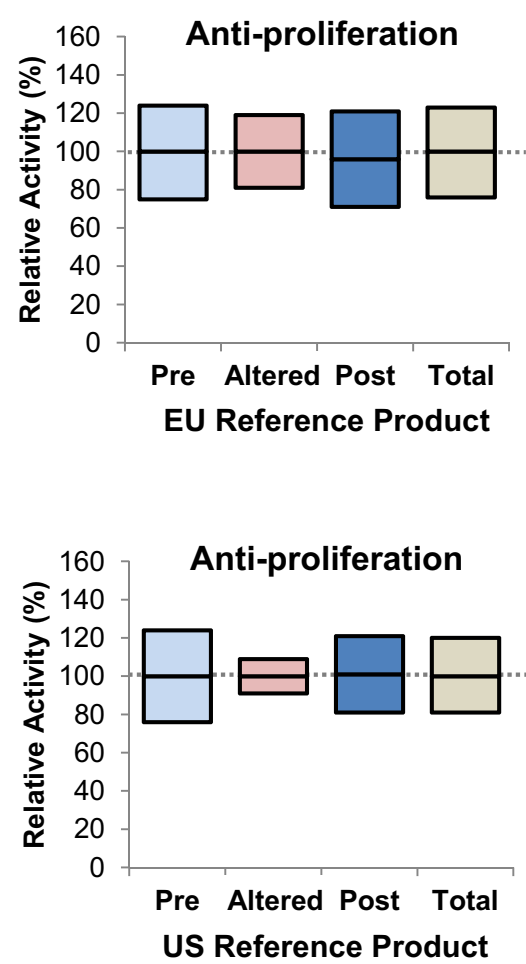

(B)
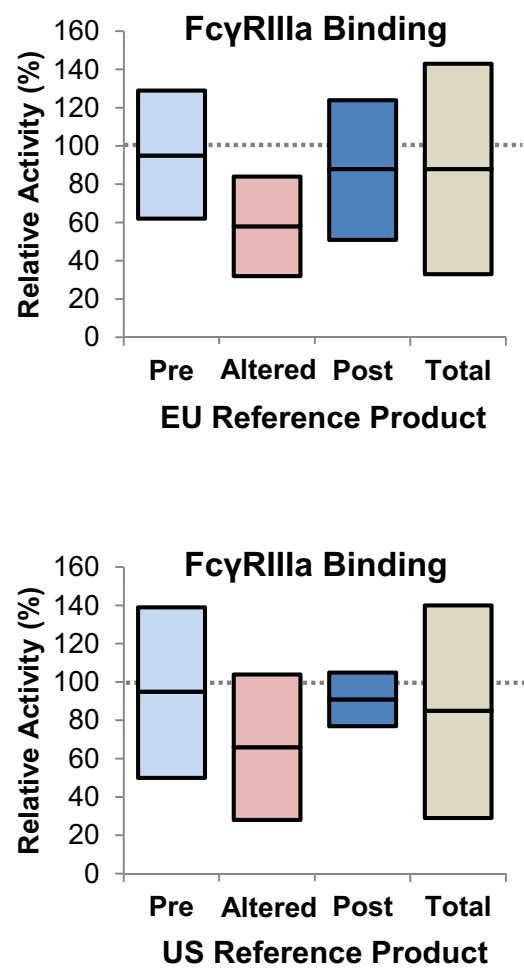

(D)
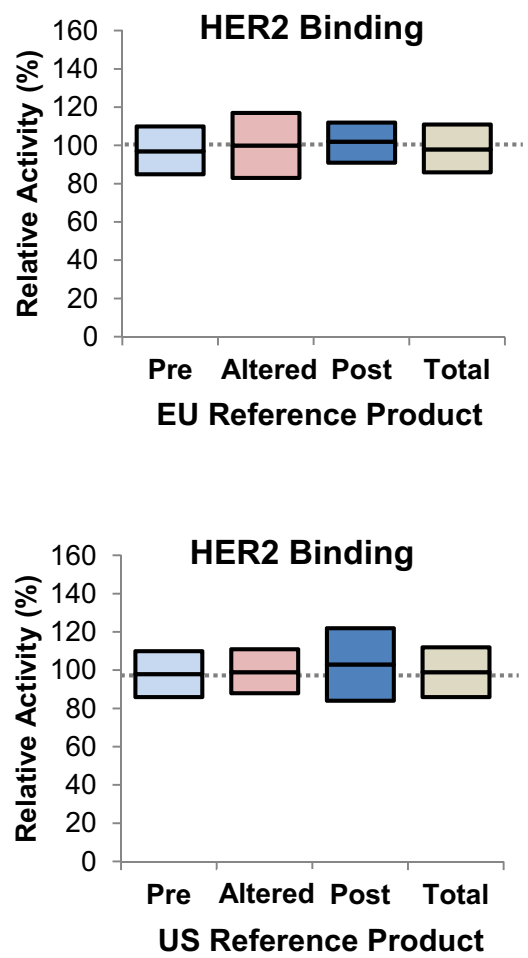
(A)

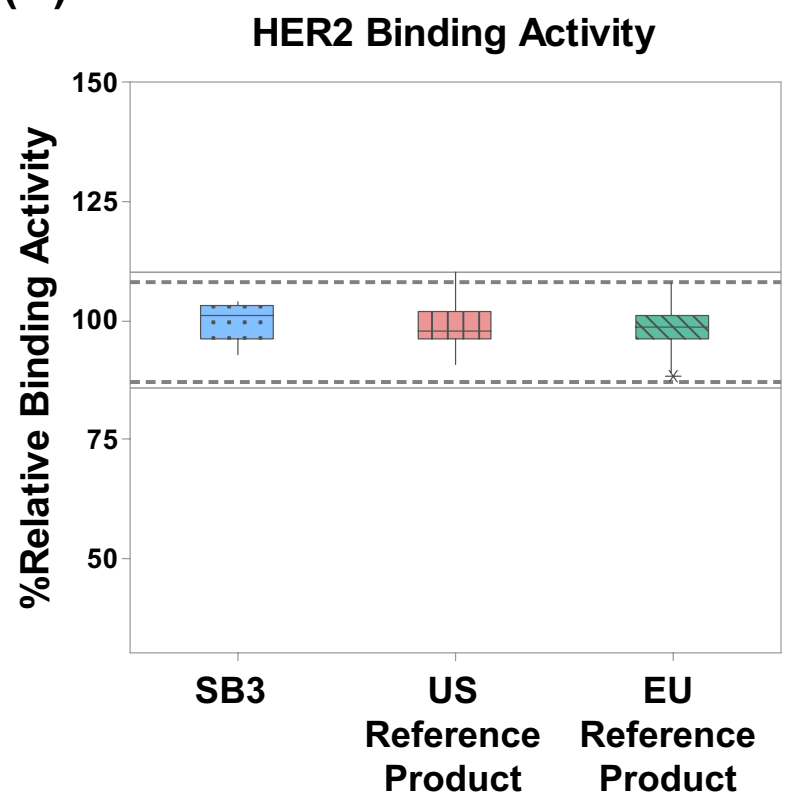

Fig. 3 Comparison of the Fab-related biological activities of SB3 and reference product. Dotted line shows the similarity range (mean $\pm 3 \mathrm{SD}$ ) of pre-altered EU-sourced reference product. Solid line shows the mean \pm 3 SD range including pre-altered and altered

potency (Fig. 3b). Therefore, these results indicate that SB3 is evidently similar to the reference product in terms of Fabrelated biological attributes.

\subsection{Fc-Related Biological Attributes}

The Fc region of trastuzumab binds to Fc $\gamma \mathrm{Rs}, \mathrm{FcRn}$, and C1q (a complement protein) for most of its effector functions and in vivo stability [23]. The interaction of the Fc region in the target-bound antibody with FcyRIIIa (a member of $\mathrm{Fc} \gamma \mathrm{Rs}$ ) on the effector cell is the key mechanism of ADCC for trastuzumab [24-26]. As CQAs of Fc-related biological attributes, ADCC, Fc $\gamma$ RIIIa binding, and FcRn binding activities were assessed to demonstrate the similarity of SB3. The mean values of relative ADCC potency for SB3 and EU- and US-sourced reference product were $98 \%, 85 \%$, and $89 \%$, respectively, and those of relative Fc $\gamma$ RIIIa binding activities were $98 \%, 84 \%$, and $88 \%$, respectively. These mean differences for ADCC and Fc $\gamma$ RIIIa binding activities are considered to result from the reference products with altered biological profiles. To verify this hypothesis, the similarity of SB3 was re-assessed with only the mean values and the similarity ranges excluding the reference products with altered biological profiles. As a result, the mean value of SB3 was similar to the quality of pre-altered reference
(B)

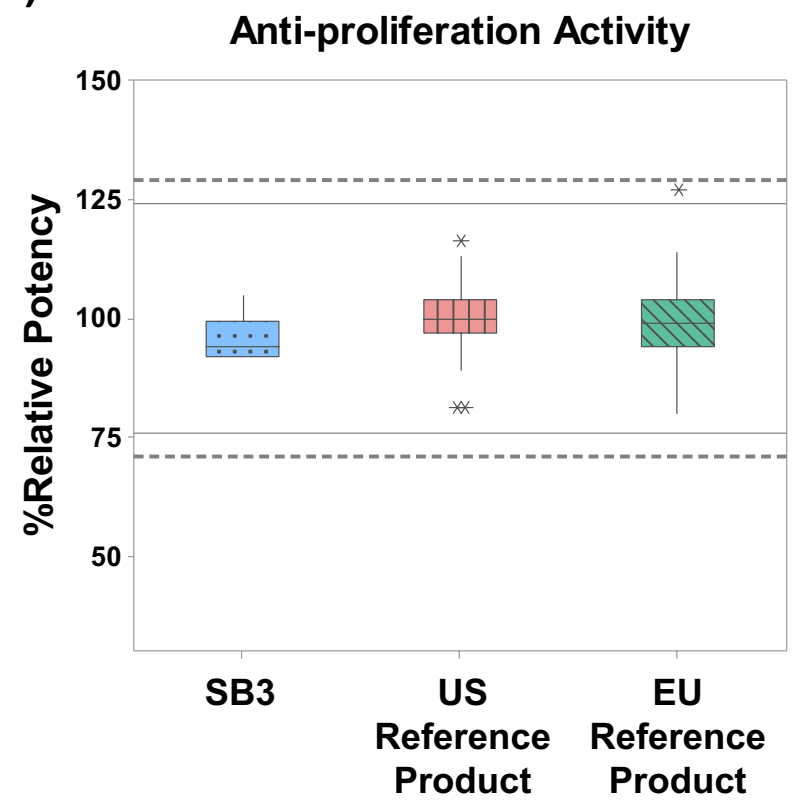

EU-sourced reference product. a HER2 binding activity and b antiproliferation activity. HER2 human epidermal growth factor receptor 2, $S D$ standard deviation

products, and all data for independent batches fell within the tightened target similarity range (Fig. 4).

Affinity binding to FcRn is critical to extend the half-life of $\mathrm{mAb}$ by recycling and exocytosis at the plasma membrane [27]. The mean values of relative FcRn binding activity for SB3 and EU- and US-sourced reference product were 96\%, $88 \%$, and $93 \%$, respectively (Fig. 4). Furthermore, all SB3 batches were within the similarity range, demonstrating similarity in FcRn binding activity.

Binding activities for other Fc $\gamma$ Rs (Fc $\gamma$ RIa, Fc $\gamma$ RIIa, and Fc $\gamma$ RIIb) were also tested as part of the similarity assessment. All Fc $\gamma$ Rs belong to the immunoglobulin superfamily and are the most important Fc receptors for inducing phagocytosis of microbes. This superfamily includes several members such as Fc $\gamma$ RI (CD64), Fc $\gamma$ RII (CD32), and FcyRIII (CD16), which differ in their affinities for antibodies and in their functions [28]. In the case of trastuzumab, ADCC would be affected by Fc $\gamma$ RIIIa rather than Fc $\gamma$ RIa, Fc $\gamma$ RIIa, and Fc $\gamma$ RIIb [29]. Therefore, the other Fc $\gamma$ Rs were categorized as non-CQA even though they should be controlled within the range to demonstrate biosimilarity. The mean values of relative binding activities for other Fc $\gamma$ Rs of SB3 were similar to reference product, summarized in Fig. 5, including the similarity ranges. In the same manner, SB3 demonstrated similarity to the reference product for 
Fig. 4 Comparison of the Fc-related biological activities of SB3 and reference product. Dotted line shows the similarity range $($ mean $\pm 3 \mathrm{SD})$ of pre-altered EU-sourced reference product. Solid line shows the mean \pm 3 SD range including pre-altered and altered EU-sourced reference product. a ADCC activity, b FcyRIIIa binding activity, and $\mathbf{c}$ FcRn binding activity. ADCC antibody-dependent cellmediated cytotoxicity, $F c \gamma R$ Fc $\gamma$ receptor, FcRn neonatal Fc receptor, $S D$ standard deviation

C1q binding activity that induces complement-dependent cytotoxicity (CDC) (Fig. 5).

Taken together, in all the SB3 batches tested, each of the Fc-related biological activities fell within the similarity range. These data strongly support the similarity of SB3 to the reference product in Fc-related as well as Fab-related attributes.

\section{Discussion}

Extensive analytical characterization is a key component for demonstrating similarity of a proposed therapeutic protein product as a biosimilar to a reference product. To understand the biological quality attributes of trastuzumab, we characterized up to 154 lots of EU- and US-sourced reference product and established reliable similarity acceptance criteria. Based on information obtained about these attributes, SB3 was developed as a trastuzumab biosimilar and approved by the EC as the first trastuzumab biosimilar in the EU. Although the analytical similarity of SB3 was assessed with quality attributes covering a wide spectrum of structural/physicochemical and functional characteristics, this study only includes functional characteristics. Briefly, the majority of biological attributes categorized as CQAs met established similarity acceptance criteria. SB3 was similar to both EU- and US-sourced reference product in Fab-related functional activities, including HER2 binding and anti-proliferation. The similarity of SB3 was also demonstrated in Fc-related attributes including ADCC, Fc $\gamma$ RIIIa binding and FcRn binding activities. Additionally, other Fc $\gamma \mathrm{R}$ binding activities conformed to the similarity range set by the reference products.

ADCC is an important MoA of trastuzumab and is significantly correlated with the level of the sum of afucosylated glycan and high mannose, as well as Fc $\gamma$ RIIIa binding activity [7]. By binding of the Fc part of IgG to FcyRIIIa (CD16) expressed on natural killer cells, target cell-bound mAbs induce ADCC. Since the affinity of Fc $\gamma$ Rs to the Fc part is influenced by $\mathrm{N}$-glycosylation, ADCC is enhanced for mAbs with lower fucosylation. The glycosylation pattern has inherent variation from one batch to another, but can also be changed in manufacturing processes [30]. Among the various features of $\mathrm{N}$-glycans, the levels of the afucosyl and high-mannose forms (labeled \%afucose and \% high mannose,
(A)

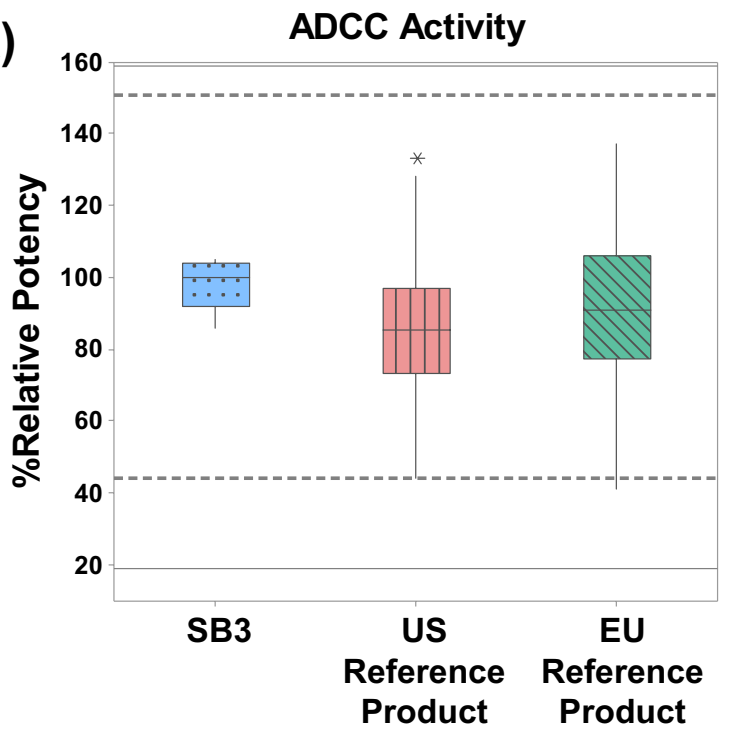

(B)

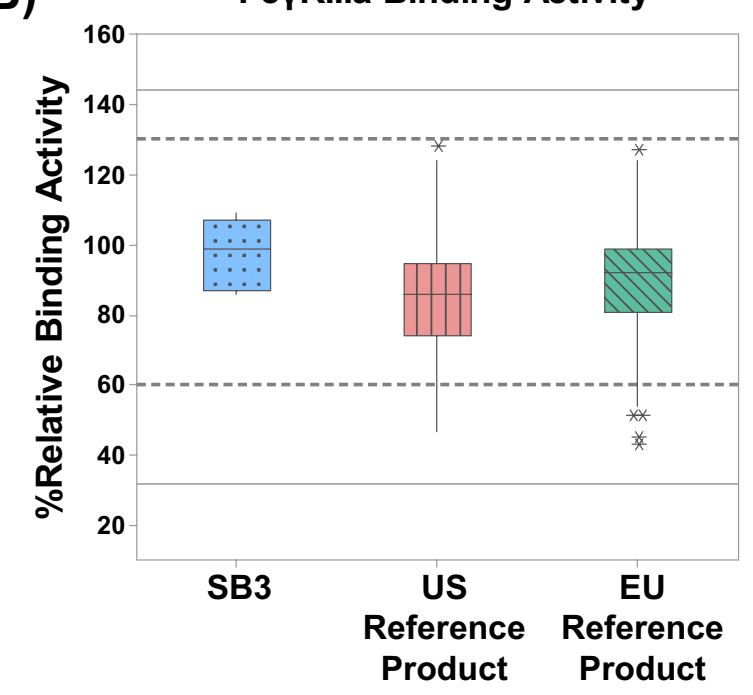

(C)

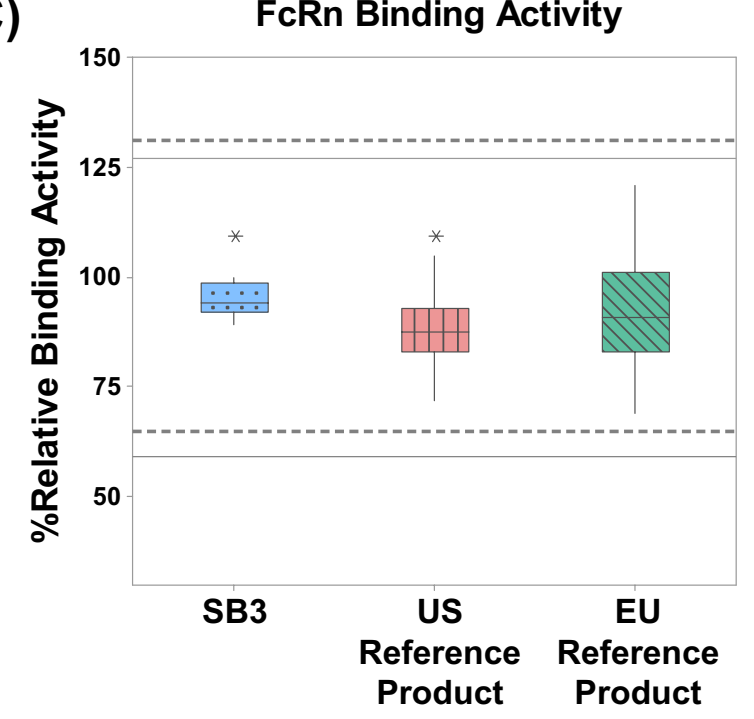


(A)

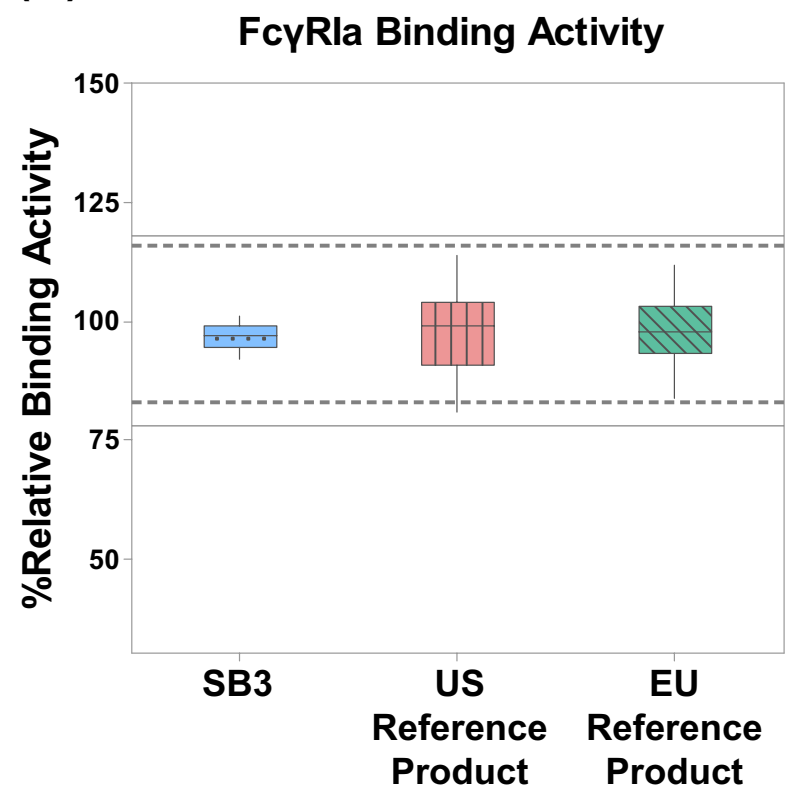

(C)

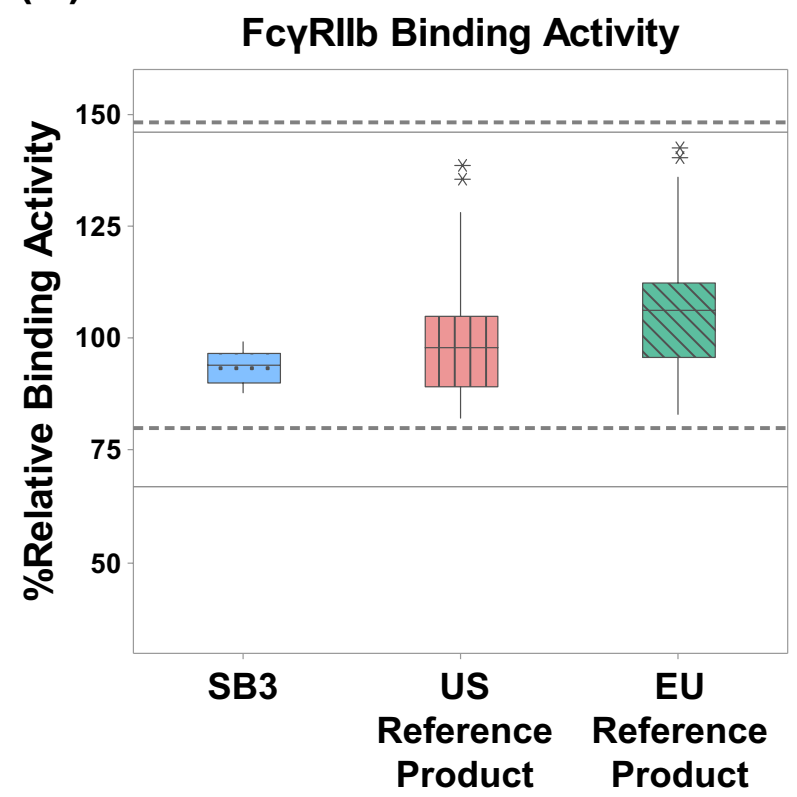

Fig. 5 Binding activities for Fc $\gamma R s$ and C1q of SB3 and reference product. Dotted line shows the similarity range (mean $\pm 3 \mathrm{SD}$ ) of pre-altered EU-sourced reference product. Solid line shows the mean \pm 3 SD range including pre-altered and altered EU-sourced ref-

respectively) correlate with ADCC and Fc $\gamma$ RIIIa binding activities, and the level of galactosylation correlates with $\mathrm{CDC}$ and $\mathrm{C} 1 \mathrm{q}$ binding activities. As discussed in Kim et al., fluctuations were observed in biological attributes including \%afucose +\%high mannose, Fc $\gamma$ RIIIa binding, and ADCC
(B)

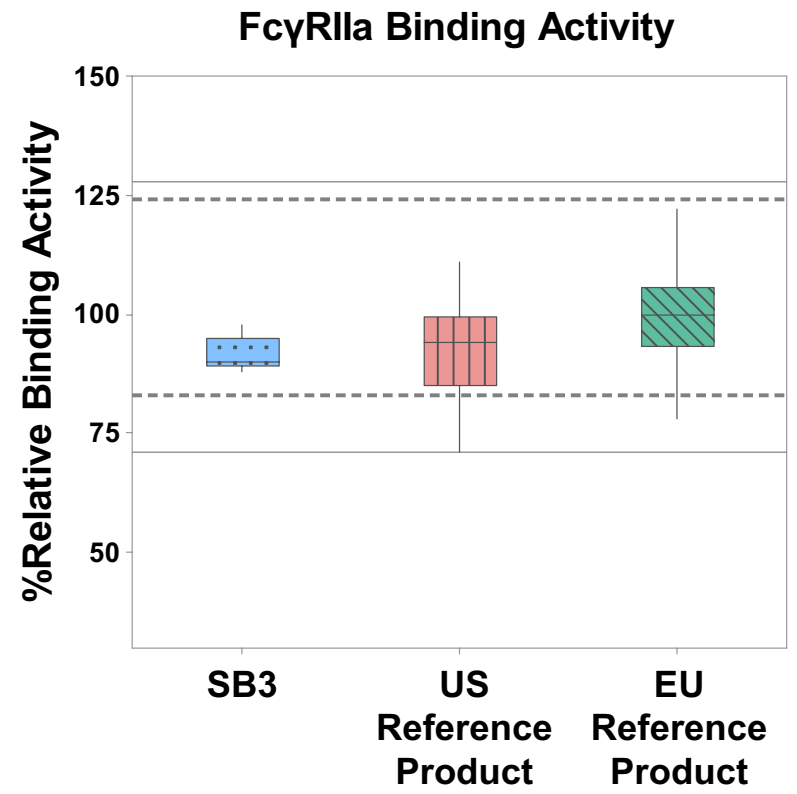

(D)

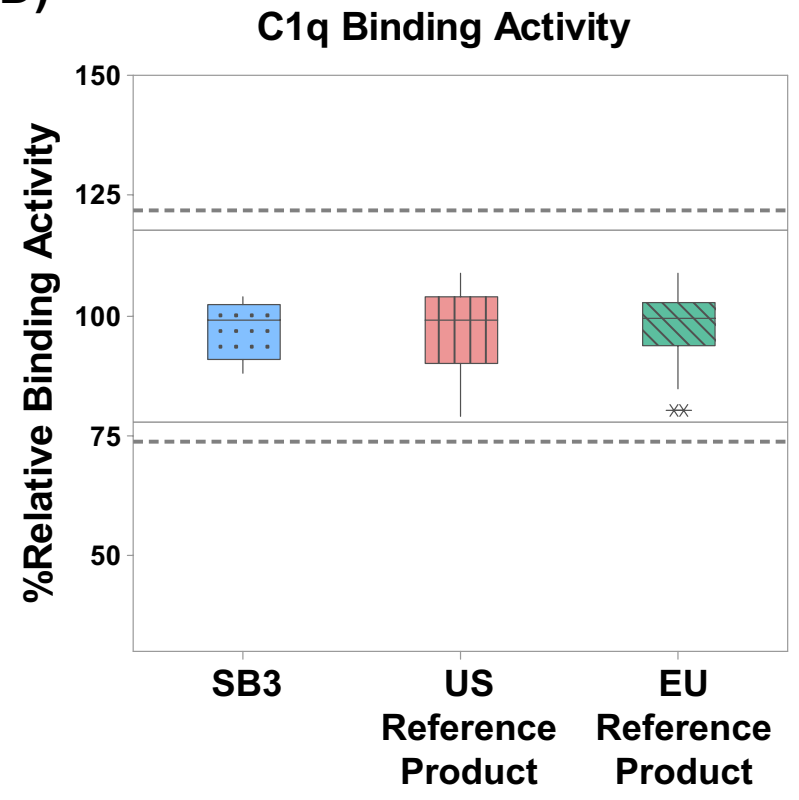

erence product. a Fc $\gamma$ RIa binding activity, b Fc $\gamma$ RIIa binding activity, $\mathbf{c}$ Fc $\gamma$ RIIb binding activity, and $\mathbf{d} \mathrm{Clq}$ binding activity. $F c \gamma R$ Fc $\gamma$ receptor, $S D$ standard deviation

in certain lots of reference products. In addition, \%galactosylation was also altered, which might affect $\mathrm{C} 1 \mathrm{q}$ binding and CDC activities. However, the C1q binding activity of the reference product was not altered during that period, which indicated that the influence of \%galactosylation change is 
not enough to affect functional activity [21]. Incorporating these fluctuations in setting the quality targets for a similarity assessment could result in broader similarity acceptance criteria. Therefore, the data from these lots displaying changed biological profiles were excluded from establishing the similarity acceptance criteria, resulting in more conservative target quality ranges for SB3. Even with the narrower quality target, the results indicated that SB3 is highly similar to the reference product in the respective Fc-related quality attributes including \%afucose $+\%$ high mannose, ADCC, and Fc $\gamma$ RIIIa binding activity (Figure 5).

Based on the reference product, the recent lots showed biological profile at the pre-change level, which means that even though the cause of the biological profile change is still unknown, the change in biological profiles was transient. The abrupt changes in biological profile also occurred in other marketed products, Rituxan ${ }^{\circledR}$ and Enbrel ${ }^{\circledR}$, which showed alterations of $\mathrm{N}$-glycan and ADCC activity as well as the reference product. According to the literature, these observed biological profile changes in the products might be caused by changes in the manufacturing processes such as cell production, growth conditions, and purification sequence [30]. However, in terms of the relevance to clinical efficacy, the influence of these alterations in biological profiles in product lots cannot be confirmed without additional clinical studies. Nevertheless, it is critical for assessing the similarity of a biosimilar product that the quality target is established without any meaningful difference from the originally approved molecular entity. As in the case of SB3, any incidental changes in the biological profile of a reference product could become a hurdle with regard to establishing the appropriate quality target, with the potential for a clinically meaningful difference in a developed biosimilar.

In conclusion, SB3 is deemed to show similar efficacy and safety to the reference product in proven indications.

Acknowledgments We would like to thank Kyung-Ah Kim for internal review and proofreading of the manuscript.

\section{Compliance with Ethical Standards}

Funding This work was funded by Samsung Bioepis Co., Ltd.

Conflict of interest The authors, Jae Hee Lee, Kyungyeol Paek, Jae Hyon Moon, Sunyoung Ham, Jinsu Song, and Seokkyun Kim, are employees of Samsung Bioepis, and declare that they have no conflict of interest.

Open Access This article is distributed under the terms of the Creative Commons Attribution-NonCommercial 4.0 International License (http://creativecommons.org/licenses/by-nc/4.0/), which permits any noncommercial use, distribution, and reproduction in any medium, provided you give appropriate credit to the original author(s) and the source, provide a link to the Creative Commons license, and indicate if changes were made.

\section{References}

1. Kirchhoff CF, Wang XZM, Conlon HD, Scott Anderson AM, Ryan Bose A. Biosimilars: key regulatory considerations and similarity assessment tools. Biotechnol Bioeng. 2017;114(12):2696-705.

2. Committee for Medicinal Products for Human Use (CHMP). Guideline on similar biological medicinal products containing monoclonal antibodies-non clinical and clinical issues. EMEA/ CHMP/BMWP/ 42832/2005 Rev1, European Medicines Agency. 2015. http://www.ema.europa.eu/docs/en_GB/document_library/ Scientific_guideline/2015/01/WC500180219.pdf.

3. Committee for Medicinal Products for Human Use (CHMP). Guideline on similar biological medicinal product. CHMP/437/04 Rev. 1. European Medicines Agency. 2014. http://www.ema.europ a.eu/docs/en_GB/document_library/Scientific_guideline/2014/10/ WC500176768.pdf.

4. Food and Drug Administration Center for Drug Evaluation and Research. Guidance for Industry: scientific considerations in demonstrating biosimilarity to a reference product. FDA2011-D-0605, U.S. Department of Health and Human Services. 2015. https://www.fda.gov/media/82647/download.

5. Food and Drug Administration Center for Drug Evaluation and Research. Guidance for Industry: Clinical pharmacology data to support a demonstration of biosimilarity to a reference product. FDA-2014-D-0234, U.S. Department of Health and Human Services. 2016. https://www.fda.gov/media/88622/download.

6. Food and Drug Administration Center for Drug Evaluation and Research. Guidance for Industry: Quality considerations in demonstrating biosimilarity of a therapeutic protein product to a reference product. FDA-2011-D-0602, U.S. Department of Health and Human Services. 2015. https://www.regulation s.gov/document?D=FDA-2011-D-0602-0051.

7. Committee for Medicinal Products for Human Use (CHMP). Guideline on similar biologic medicinal products containing biotechnology derived protein as active substance: quality issue (revision 1). EMA/CHMP/BWP/247713/2012, European Medicines Agency. 2014. http://www.ema.europa.eu/docs/en_GB/docum ent_library/Scientific_guideline/2014/06/WC500167838.pdf.

8. Nahta R, Yu D, Hung MC, Hortobagyi GN, Esteva FJ. Mechanisms of disease: understanding resistance to HER2-targeted therapy in human breast cancer. Nat Clin Pract Oncol. 2006;3(5):269-80.

9. Nixon NA, Hannouf MB, Verma S. The evolution of biosimilars in oncology, with a focus on trastuzumab. Curr Oncol. 2018;25:S171-9.

10. Yu T, Claret FX. Trastuzumab: updated mechanisms of action and resistance in breast cancer. Front Oncol. 2012;2:62.

11. Browne BC, O'Brien N, Duffy MJ, Crown J, O'Donovan N. HER-2 signaling and inhibition in breast cancer. Curr Cancer Drug Targets. 2009;9(3):419-38.

12. Goldenberg MM. Trastuzumab, a recombinant DNA-derived humanized monoclonal antibody, a novel agent for the treatment of metastatic breast cancer. Clin Ther. 1999;21(2):309-18.

13. Baselga J, Albanell J. Mechanism of action of anti-HER 2 monoclonal antibodies. Ann Oncol. 2001;12(1):S35-41.

14. Beano A, Signorino E, Evangelista A, Brusa D, Mistrangelo M, Polimeni MA, Spadi R, Donadio M, Ciuffreda L, Matera L. Correlation between $\mathrm{NK}$ function and response to trastuzumab in metastatic breast cancer patients. J Transl Med. 2008;16(6):25.

15. Arnould L, Gelly M, Penault-Llorca F, Benoit L, Bonnetain F, Migeon C, Cabaret V, Fermeaux V, Bertheau P, Garnier J, Jeannin JF, Coudert B. Trastuzumab-based treatment of HER2-positive breast cancer: an antibody-dependent cellular cytotoxicity mechanism? Br J Cancer. 2006;94(2):259-67. 
16. Klapper LN, Waterman H, Sela M, Yarden Y. Tumor-inhibitory antibodies to HER-2/ErbB-2 may act by recruiting c-Cbl and enhancing ubiquitination of HER-2. Cancer Res. 2000;60(13):3384-8.

17. Nelson KM, Gallagher PC. Biosimilars lining up to compete with Herceptin-opportunity knocks. Expert Opin Ther Pat. 2014;24(11):1149-53.

18. Pivot X, Curtit E, Lee YJ, Golor G, Gauliard A, Shin D, Kim Y, Kim H, Fuhr R. A randomized phase I pharmacokinetic study comparing biosimilar candidate SB3 and trastuzumab in healthy male subjects. Clin Ther. 2016;38(7):1665-73.

19. Li C, Wang B, Chen SC, Wada R, Lu D, Wang X, Polhamus D, French J, Vadhavkar S, Strasak A, Smitt M, Joshi A, Samant M, Quartino A, Jin J, Girish S. Exposure-response analyses of trastuzumab emtansine in patients with HER2-positive advanced breast cancer previously treated with trastuzumab and a taxane. Cancer Chemother Pharmacol. 2017;80(6):1079-90.

20. Repka T, Chiorean EG, Gay J, Herwig KE, Kohl VK, Yee D, Miller JS. Trastuzumab and interleukin-2 in HER2-positive metastatic breast cancer: a pilot study. Clin Cancer Res. 2003;9(7):2440-6.

21. Kim S, Song J, Park S, Ham S, Paek K, Kang M, Chae Y, Seo H, Kim HC, Flores M. Drifts in ADCC-related quality attributes of trastuzumab $^{\circledR}$ : impact on development of a trastuzumab biosimilar. MAbs. 2017;9(4):704-14.

22. Higel F, Seidl A, Sörgel F, Friess W. N-glycosylation heterogeneity and the influence on structure, function and pharmacokinetics of monoclonal antibodies and $\mathrm{Fc}$ fusion protein. Eur J Pharm Biopharm. 2016;100:94-100.

23. Mellor JD, Brown MP, Irving HR, Zalcberg JR, Dobrovic A. A critical review of the role of $\mathrm{Fc}$ gamma receptor polymorphisms in the response to monoclonal antibodies in cancer. J Hematol Oncol. 2013;6:1.

24. Tamura K, Shimizu C, Hojo T, Akashi-Tanaka S, Kinoshita T, Yonemori K, Kouno T, Katsumata N, Ando M, Aogi K, Koizumi
F, Nishio K, Fujiwara Y. Fc $\gamma$ R2A and 3A polymorphisms predict clinical outcome of trastuzumab in both neoadjuvant and metastatic settings in patients with HER2-positive breast cancer. Ann Oncol. 2011;22(6):1302-7.

25. Musolino A, Naldi N, Dieci MV, Zanoni D, Rimanti A, Boggiani D, Sgargi P, Generali DG, Piacentini F, Ambroggi M, Cagossi K, Gianni L, Sarti S, Bisagni G, Ardizzoni A, Conte PF, Guarneri $\mathrm{V}$. Immunoglobulin $\mathrm{G}$ fragment $\mathrm{C}$ receptor polymorphisms and efficacy of preoperative chemotherapy plus trastuzumab and lapatinib in HER2-positive breast cancer. Pharmacogenomics J. 2016;16(5):472-7.

26. Collins DM, O’Donovan N, McGowan PM, O'Sullivan F, Duffy MJ, Crown J. Trastuzumab induces antibody-dependent cell-mediated cytotoxicity (ADCC) in HER-2-non-amplified breast cancer cell lines. Ann Oncol. 2012;23(7):1788-95.

27. Ward ES, Devanaboyina SC, Ober RJ. Targeting FcRn for the modulation of antibody dynamics. Mol Immunol. 2015;67:131-41.

28. Musolino A, Naldi N, Bortesi B, Pezzuolo D, Capelletti M, Missale G, Laccabue D, Zerbini A, Camisa R, Bisagni G, Neri TM, Ardizzoni A. Immunoglobulin $\mathrm{G}$ fragment $\mathrm{C}$ receptor polymorphisms and clinical efficacy of trastuzumab-based therapy in patients with HER-2/neu-positive metastatic breast cancer. J Clin Oncol. 2008;26(11):1789-96.

29. Mellor JD, Brown MP, Irving HR, Zalcberg JR, Dobrovic A. A critical review of the role of $\mathrm{Fc}$ gamma receptor polymorphisms in the response to monoclonal antibodies in cancer. J Hematol Oncol. 2013;4(6): 1

30. Schiestl M, Stangler T, Torella C, Cepeljnik T, Toll H, Grau R. Acceptable changes in quality attributes of glycosylated biopharmaceuticals. Nat Biotechnol. 2011;29(4):310-2. 